\title{
La neumología en tiempos de COVID
}

\section{Respiratory medicine and COVID times}

\author{
Jesús J. Vázquez-Cortés*
}

*Presidente de la Sociedad Mexicana de Neumología y Cirugía de Tórax.

En febrero de 2020, llegó a México la pandemia COVID-19; sin duda, ha puesto a prueba a todo el sistema de salud, tanto público como privado, con gran repercusión en todos los ámbitos que tienen que ver con la atención, la organización, la operación y la educación médica en todos los niveles. Nuevamente, los especialistas en neumología, igual que en la pandemia de influenza A H1N1 de 2009, junto con otros especialistas afines, principalmente de medicina crítica y de urgencias e infectología, se posicionaron como uno de los recursos humanos más importantes para atender un problema de salud de esta magnitud y gravedad. A todos los especialistas en enfermedades respiratorias nos tocó apoyar y sostener al sistema de salud con entusiasmo, tiempo, conocimientos, experiencia y pasión; sin dejar de pensar que también pasamos por periodos de cansancio, miedo, tristeza, frustración y agotamiento.

\section{¿QUÉ PERDIMOS EN EL CAMINO?}

La peor pérdida fue de personas, todos padres, madres, hermanos, familiares o amigos; a pesar de intentar evitarlo hasta donde nos fue posible, la enfermedad les provocó la muerte. Desafortunadamente, muchas de esas pérdidas humanas corresponden a personal de la salud: médicos, enfermeras, técnicos, camilleros y otros, quienes en el cumplir de sus labores, se contagiaron y desarrollaron una forma grave e irreversible de la enfermedad. A todos ellos nuestro mayor reconocimiento, quedarán por siempre en nuestra memoria.

Correspondencia:

Jesús J. Vázquez-Cortés

Presidente de la Sociedad Mexicana de Neumología

y Cirugía de Tórax.

Correo electrónico: lungdoc@prodigy.net

Citar como: Vázquez-Cortés JJ. La neumología en tiempos de COVID. Neumol Cir Torax. 2021; 80 (3): 164-165. https://dx.doi.org/10.35366/102475
Por otra parte, quiero hacer mención de dos de los mayores impactos relacionados con la neumología; la primera es la atención de los pacientes con enfermedades respiratorias «habituales», como los pacientes con tuberculosis, EPOC, asma grave, fibrosis pulmonar y cáncer de pulmón, entre otras; la segunda, la pérdida académica en el pregrado y posgrado de la especialidad.

En 2019, se calculaban 22 mil casos nuevos de tuberculosis cada año, gracias al Programa Nacional de Tuberculosis, eran atendidos y tratados con éxito en los sistemas de salud estatales o en centros como el IMSS, INER o el Hospital General de México. Desde la pandemia, estos sistemas de salud y muchos otros hospitales tuvieron obligadamente que convertirse en centros de atención COVID, lo que impidió a los enfermos acceder a su atención habitual. Lo mismo ha pasado con los pacientes con otras patologías respiratorias, por ejemplo, los pacientes con EPOC se han mantenido, en general, cuidándose en casa, esto ha provocado que se movilicen poco y han ganado peso, lo que dificulta y deteriora su calidad de vida, a pesar del tratamiento. De igual forma para otros pacientes, ¿dónde están y cómo están siendo tratados los casos con cáncer de pulmón, con asma grave o con fibrosis pulmonar?

Desde el punto de vista de educación médica, los estudiantes de pregrado perdieron muchas sedes académicas debido a la necesidad de los centros hospitalarios de atender pacientes COVID. Esto les impidió asistir de manera presencial a clases y visitas hospitalarias supervisadas, una grave afectación. Hasta ahora, los estudiantes de campos clínicos han perdido casi cuatro semestres. Sin embargo, siguen avanzando en sus ciclos clínicos sin la posibilidad no sólo de aprender, sino de desarrollar el «sentido común médico» que se adquiere desde el inicio de la vida hospitalaria.

La enseñanza de posgrado no se vio menos afectada, los médicos residentes fueron, de manera ejemplar, la primera línea de batalla contra el virus, pero perdieron parte de su entrenamiento en el resto de la neumología, dejando atrás la oportunidad de estudiar, aprender, aplicar y desarrollar lo «fino» de las patologías y tratamientos de la especialidad. 


\section{¿QUÉ HEMOS APRENDIDO?}

No todo fue malo, como nunca, especialistas en todo el país, residentes de neumología y áreas afines, luchamos y seguimos siendo junto a nuestro personal de enfermería y paramédico, el primer frente contra la terrible situación y condición a la que nos ha llevado la infección por SARSCoV-2; seguimos luchando por rescatar y atender lo mejor posible a cada enfermo con COVID-19. Como desde hace más de 18 meses, el trabajo en equipo, la humildad, la resiliencia y la ética del actuar médico se han antepuesto a cualquier otro interés.

Mi más sincero reconocimiento a todos los neumólogos, residentes de neumología, enfermeras, camilleros, terapistas respiratorios, rehabilitadores y administrativos, y a todo el personal que de una u otra forma han participado incansablemente en la atención de los pacientes con COVID. 